\title{
Corporate Leadership Strategy Management Based on Entropy Coupling Algorithm
}

\author{
Zhaoyang Wu $\mathbb{D}^{1,2}$ James Yong Liao, ${ }^{2}$ Shiyong Wang, ${ }^{1}$ Jiaoyao Ji, ${ }^{3}$ and Xiaokui Zhao' \\ ${ }^{1}$ School of Economics and Management, Qinghai Normal University, Xi'ning 810016, Qinghai, China \\ ${ }^{2}$ Center of International Education, Philippine Christian University, Malate, Manila 1004, Philippines \\ ${ }^{3}$ The People's Procuratorate of Shanghai Hudong District, Hongkou, Shanghai 200000, China \\ Correspondence should be addressed to Zhaoyang Wu; 2018130@qhnu.edu.cn
}

Received 13 May 2021; Revised 16 June 2021; Accepted 2 July 2021; Published 9 July 2021

Academic Editor: Sang-Bing Tsai

Copyright ( 92021 Zhaoyang Wu et al. This is an open access article distributed under the Creative Commons Attribution License, which permits unrestricted use, distribution, and reproduction in any medium, provided the original work is properly cited.

With the continued economic downturn, coupled with the slowdown of domestic economic development and fierce market competition, the development of small and medium-sized enterprises has become more and more difficult. Because the financial background and operating strength of small and medium-sized enterprises are far inferior to large-scale enterprises, coupled with the influence of global economic integration, many small and medium-sized enterprises have gradually closed down. Therefore, exploring the entropy coupling algorithm is of great significance to the role of corporate leadership strategy management. This paper studies the coupling conditions and coupling process of corporate strategy and business model, builds a new coupling model, and goes deep into the coupling model to study the cooperation mechanism between its internal modules and initially builds the company to break through the two major dilemmas at the same time. This paper uses entropy theory to evaluate corporate leadership strategy, constructs an evaluation index system based on entropy, determines the weight of each index, and calculates the entropy value. This paper uses the alpha coefficient to test the reliability of the questionnaire. The value range of $\alpha$ coefficient is $[0,1]$, and different values represent different reliability. Large enterprises as a whole are mostly in the highly coupled (41.80\%) and moderately coupled (27.34\%) stages; medium-sized enterprises as a whole are mostly in the highly coupled (39.50\%) and moderately coupled (31.50\%) stages; small enterprises as a whole are mostly in the moderately coupled (39.50\%) and moderately coupled (40.72\%), low coupling (33.20\%), and high coupling (25.9\%) stages; microenterprises as a whole are mostly in the low coupling (43.70\%), moderate coupling (36.41\%), and high coupling (30.51\%) stages. The results show that the entropy coupling algorithm can improve the deficiencies in the leadership strategy and provide a practical and reliable path for carrying out leadership development projects.

\section{Introduction}

Economic globalization has not only reconstructed people's ideas and concepts but also deconstructed traditional thoughts and continuously innovated management concepts. The scale and speed of enterprise production and operation activities have grown rapidly, and the complexity, diversity, and diversification have reached unprecedented levels. Some enterprises mainly rely on outsourcing management training courses for leadership development, which promotes the popularization of some basic management tools and concepts and also promotes the enterprise management to have some common language in daily management activities. However, due to the lack of close integration with enterprise practice and the failure to form an environment for the application of new skills or methods in the enterprise, it is difficult to really change the behavior of managers at work and even more difficult to promote the enterprise to effectively respond to change.

The research method of this paper uses cross-case studies, mainly using grounded theory to introduce the successful experience of three companies, the mechanism of innovation coupling and the evaluation process of coupling degree, and the evaluation process of the company's own technological innovation and institutional innovation coupling in practice. For the enterprise management team, 
knowledge work is the main task of the management team. Each team member has considerable professional knowledge and ability, which plays an important role in the development of the team. Their common characteristic is that their leading needs are at a high level, such as society, respect, and self-realization; team members expect more work autonomy and more opportunities to influence teamwork and participate in leadership.

Strategic management of corporate leadership is essential to the development of a company. Kasztelnik summarized the arguments and rebuttals in scientific discussions regarding the perception of effective policing by leading cadres through diversified training and learning outcomes and cultural capabilities. His main purpose is to explore whether and to what extent the leadership of law enforcement agencies has learned the results of the diversity training program, and the impact of the leadership's cultural ability on the effectiveness of law enforcement organizations. By determining whether there is a significant difference in the effectiveness of the police when incorporating the learning outcomes of the diversity training initiative, he expanded the police leadership knowledge base cultural capabilities to include both proprietary and collective capabilities. The relevance of this scientific decision is that the police leadership has the knowledge and actively understands the effectiveness of the police through diversity training. The learning results and cultural abilities can be adapted and adjusted to meet the needs of black and multicultural commuting. Although his research shows that the statistical significance of the effectiveness of multitraining active learning in predicting police effectiveness is considerable, it lacks a specific experimental process [1]. Putra believes that leadership is a much-researched topic. However, as an important factor for every organization, leadership has largely contributed to the failure of the company, especially in small independent catering companies, which may be due to the unique operation of the industry and the lack of leadership for small hotel companies power research. He aims to fill this gap by using qualitative research methods to explore the ideal characteristics of small independent restaurant leaders to become effective leaders from the perspective of employees. Qualitative data was collected through four focus groups and a binary interview. Although his research has a certain reference value, it lacks innovation [2]. Hdrolu believes that the number of new leadership theories is increasing day by day. Strategic leaders have the ability to influence all business followers by successfully applying strategic management tools to organizational processes. After briefly introducing the relevant knowledge of strategic leadership style, he discussed the difference between strategic leadership style and other leadership styles; he will discuss how legendary strategic leadership skills can effectively influence corporate strategy during the COVID-19 epidemic. Although his research is relatively comprehensive, it lacks accuracy [3]. Tharwat believes that entrepreneurial leadership with a purely intellectual starting point has attracted the attention of high-quality international business organizations because it requires leaders with strategic thinking, which can change with the changes in the surrounding environment. Therefore, due to the emergence of globalization as well as the cognitive economy and technological progress, the complex environmental conditions surrounding these organizations have accelerated, and people have become interested in the theme of strategic thinking corporate leadership. This may be manifested in artificial intelligence technology, which encourages these leaders and their organizations to a mechanism for finding continuity and stability in a competitive world. Therefore, it is expected that entrepreneur leaders have the quality of intellectual motivation, which is an important issue of entrepreneurial leadership. This will help them realize the vision of the organization and realize the local and global entrepreneurial spirit. Therefore, he is committed to understanding the impact of artificial intelligence on the entrepreneurial spirit of the leadership of international business organizations, with a view to realizing the added value of its strategic operations at the local and global levels. Although his research shows that leadership has added value, his research lacks necessary data [4].

This paper describes the path and mechanism of the effect of enterprise leadership development on enterprise performance and improves the research on the influencing factors of enterprise performance in strategic management. This paper examines the relationship between strategic leadership and the performance of top managers; at the same time, it puts forward the influence of the matching between the strategic style of the top managers and the strategic stage of the enterprise on the enterprise performance and makes empirical research and test.

\section{Corporate Leadership Strategy Management}

2.1. Entropy Coupling Algorithm. The entropy method is based on the difference of information contained in the indicators, completely using the original indicator data information, that is, the inherent information of the indicator data to determine the utility value of the indicator, thereby determining the entropy weight of each indicator. In the target evaluation system, the operator needs to consider the importance of each index and assign weight to it [5]. The higher the utility value of the evaluation index, the greater the degree of variation, the greater the information-carrying capacity of the index, and the higher the weight; for the secondary evaluation index, the degree of variation is less, the amount of information is less, and the weight is also higher. The main idea of low entropy weight is to take the information-carrying capacity of each evaluation index as the weighting standard and give different weights to each index by the amount of its information [6].

The coupling degree model of the interaction of multiple systems is

$$
C_{m}=\left\{\frac{\left(U_{1} \cdot U_{2} \ldots U_{m}\right)}{\left[\prod\left(U_{i}+U_{j}\right)\right]}\right\}^{1 / m}
$$

The coupling degree function of enterprise technological innovation and institutional innovation is as follows [7]: 


$$
C=\left\{\frac{\left(U_{1} \cdot U_{2}\right)}{\left[\left(U_{1}+U_{2}\right) \cdot\left(U_{1}+U_{2}\right)\right]}\right\}^{1 / 2} .
$$

According to the definition of system risk conduction energy, there should be [8]

$$
E_{i}(t)=h_{i}(Y(t, i), \bar{Y}(t, i)) .
$$

Among them, $h_{i}$ is the projection operator of $R^{n} \longrightarrow R^{k}$, which represents the directed distance between the state of the risk conduction factor and its ideal state [9]. At time $t$, the risk conduction energy of the system should be

$$
\operatorname{ER}(t)=\sum_{i=1}^{k} e_{i}=\sum_{i=1}^{k} h_{i}(Y(t, i), \bar{Y}(t, i)) .
$$

For the single-factor risk transmission process, the equation form is as follows:

$$
\left\{\begin{array}{l}
\mathrm{d} Y_{i}(t)=f_{i}\left(X_{j}(t)\right) \mathrm{d}(t)+\sigma_{i j} \mathrm{~d} B(t) \\
\bar{Y}=f(\bar{X}(t)) .
\end{array}\right.
$$

Among them, $\bar{Y}$ is the state of risk conduction factors when the risk conduction energy is at the zero points of energy [10].

For the risk transmission process under the influence of multiple factors, the situation is much more complicated. It is necessary to establish a stochastic differential equations model, which has the following form:

$$
\left\{\begin{array}{l}
\mathrm{d} Y_{i}(t)=f_{i}\left(X_{j}(t)\right) \mathrm{d}(t)+\sigma_{i j} \mathrm{~d} B(t), \\
\bar{Y}_{i}=f_{i}\left(\bar{X}_{j}(t)\right) .
\end{array}\right.
$$

In the formula, $\sigma_{i j}$ is an $m \times n$ matrix; let $M=f_{i}\left(X_{j}(t)\right)$; then $M$ is an $m$-dimensional vector [11].

Let $\left\{f_{t}(\sigma)\right\}$ and $\left\{f_{t}\left(\sigma^{\prime}\right)\right\}$ represent the simulated value and the real value, respectively, and then construct the simulated sample moment SME [12]:

$$
\operatorname{SME}_{T}(\sigma)=\frac{1}{T} \sum_{t=1}^{T}\left\{f_{t}(\sigma)-\frac{1}{\tau(t)} Z \sum_{S=1}^{\tau(t)} f_{t}\left(\sigma^{\prime}\right)\right\} .
$$

The two coupled industries are firstly independent of each other and have not yet undergone industry integration or substitution. Secondly, the change of variables in one industry has an indirect impact on the other industry and has a cross-response relationship between production links. The emergence of diversified enterprises has decentralized the occurrence of industrial coupling to the internal enterprise, turning the exchange of resources between enterprises into the material exchange between enterprise departments, thereby reducing the transaction cost of industrial coupling [13].

From the perspective of the enterprise, the diversification strategy aims to improve its own profits and efficiency and enhance the core competitiveness of the enterprise, but from the perspective of the industry, the diversification of the enterprise is important for the adjustment of resources and the coordinated development of the industrial groups involved in the enterprise. The significance of this interindustry coupling is more convenient [14]. In the current economic landscape, the power of enterprises, especially large enterprise groups, has gradually become the third economic force between government forces and market forces. The government and the market dominate the trend of economic trends [15]. Due to the control of production resources by large enterprise groups, the attraction of social capital, and the separation of product markets, enterprises are actually the functional subjects of industrial activities and evolution, and the production organization method of enterprises determines the efficiency of industrial operations to some extent [16].

2.2. Corporate Leadership Strategy. With the evolution of the world and the increasing transparency of geographic boundaries, it is urgent for managers to understand the composition of global leadership. A global leader understands that it is difficult to accept an international mission and therefore requires a lot of preliminary preparation. The global leader knows his people, the perspectives of all parties, and his weaknesses and strengths, and he is happy to learn about cross-cultural knowledge to equip his overall capabilities. Ultimately, good global leaders are both effective and efficient because they have high levels of cultural, emotional, and social intelligence, and they are fully prepared for the challenges of globalization $[17,18]$.

When the business of an enterprise or a department is in a dilemma, people always hope that the supervisor can take timely and appropriate action. An action is appropriate because it is based on strong facts. However, there are more and more variables in the current business environment, and the frequency of occurrence is also faster and faster. When opportunities or crises become clear, there is usually no time to use or avoid them. In the old economic environment of simple and repetitive work, what the company needs most is the executive's ability to stick to the rules and say the same thing. However, as an enterprise manager who can challenge today's changeable business environment, first of all, he should have a positive and active attitude, rather than sticking to the rules and passively waiting for the orders of the superior; secondly, they have a solid professional foundation and flexible ability of analysis and judgment. After forming enough self-confident self-judgment, the next step is to establish the vision and goal of the team and point out the analysis for the team members [19].

The modern, highly informatized, and knowledge-based flat organizational structure has changed the traditional topdown pyramidal organizational relationship structure formed by simple repetitive labor. In modern society, people are consciously or unconsciously exercising in all aspects of work, study, and life leadership. Of course, the leadership requirements for managers in modern enterprises are getting higher and higher [20].

Assume that the variable $U_{i}$ is the order parameter of technological innovation and institutional innovation, and $U_{i j}$ is the $j$-th index of the $i$-th order parameter, which is the internal factor of technological innovation and institutional 
innovation, and its value is $X_{i j}(j=1,2,3,4) . A_{i j}$ and $B_{i j}$ are the upper and lower limits of the time series parameters of the stable state of enterprise technology and institutional innovation system [21]. The orderly efficacy coefficients of the elements of technological innovation and institutional innovation are

$$
U_{i j}=\left\{\begin{array}{l}
\frac{\left(X_{i j}-B_{i j}\right)}{\left(A_{i j}-B_{i j}\right)}, \\
\frac{\left(A_{i j}-X_{i j}\right)}{\left(A_{i j}-B_{i j}\right)} .
\end{array}\right.
$$

Since technological innovation and institutional innovation are two different and interacting systems, we use the linear weighted sum method to calculate the "total contribution" of each factor indicator:

$$
\begin{aligned}
U_{i} & =\sum_{j=1} \lambda_{i j} U_{i j}, \\
\sum \lambda_{i j} & =1 .
\end{aligned}
$$

Among them, $\lambda_{i j}$ is the weight of each index of $U_{i j}$ [22, 23].

By analyzing the characteristics and development status of high-tech enterprises, it is found that the development trend of high-tech enterprises is on the rise, which is reflected in not only the expansion of scale and the increase of sales revenue and profit but also the improvement of the level of technological innovation. This kind of development has made the influence of high-tech enterprises on the national economy more and more, and the country should pay more attention to and attach importance to the sustainable and healthy growth of high-tech enterprises [24]. From the perspective of the development characteristics of high-tech enterprises and the comparison with traditional enterprises, high-tech enterprises have a relatively high demand for technological innovation and grow faster, but at the same time, the risk of the enterprise is relatively large, and the input of human, financial, and material resources is relatively large. The product and technology update speed is relatively fast; this result is bound to lead to the fact that enterprises not only need to pay attention to technological innovation but also need to have a complete and suitable institutional system so that they can be effective and efficient under the rapidly changing market and a large number of resources (rapid technological innovation [25]).

\section{Enterprise Leadership Strategy Management Experiment}

3.1. Selection of Sample Objects. The industry choices of diversified companies are divided into two categories: related diversification and nonrelated diversification. Among them, related diversification involves industries that have higher relevance and have higher similarities or similarities in production technology, management experience, and resource markets. The degree of overlap and the probability of coupling between the involved industries are higher, and the adjustment of enterprises between industries is more flexible and convenient. Therefore, relevant diversified enterprises can better have the effect of interindustry coordination and realize economies of scope, and their advantages in industrial coupling are more obvious. Therefore, this paper selects diversified companies with strong industry relevance as the empirical research object [26].

\subsection{Determination of the Weight of the Evaluation Index Based} on Entropy. This article selects evaluation indicators and constructs an evaluation indicator system, the purpose of which is to evaluate the leadership of the enterprise. Since the importance of each index in the evaluation index system to leadership strategy is different, it is necessary to determine the weight of the index. This article uses the method of expert scoring to give weight to the indicator. This paper selects five experts and scholars and requires the selected five experts and scholars to make an objective evaluation of the evaluation indicators of corporate leadership innovation from both theoretical and practical aspects. We use the scaling method to construct the pairwise comparison judgment matrix, use the characteristic root method to calculate the weight, and then perform the consistency test, calculate the consistency index $\mathrm{CI}=$ (the maximum characteristic of the judgment matrix $\lambda-n) /(n-1)$, and calculate the consistency rate (CR) [27]. With the development of internal management and external information exchange, positive entropy change and negative entropy change compete and restrict each other in enterprises, and the advantages of one of them will be gradually revealed: when the enterprise's financial situation is good and continues to maintain a good trend, the degree of negative entropy change is stronger than that of positive emotion change; when the enterprise's financial situation is poor and there is a trend of deterioration, the degree of positive entropy change is stronger than that of negative entropy change.

\subsection{Construction of Corporate Leadership Strategy Evaluation} Model. This paper uses entropy theory to evaluate corporate leadership strategy, which is based on traditional performance evaluation indicators, constructs an evaluation index system based on entropy, determines the weight of each indicator, calculates the entropy value, and reflects the collaborative innovation situation of the evaluation object according to the change of entropy value. The larger the entropy value, the greater the disorder of the corporate leadership innovation system. In order to improve corporate leadership innovation performance, effective measures must be taken to reduce the increase in entropy and improve the order of the corporate leadership innovation system [28].

3.4. Reliability and Validity of the Questionnaire. This paper uses coefficient $\alpha$ to test the reliability of the questionnaire. The value range of the coefficient $\alpha$ is $[0,1]$. The correlation between the reliability of the questionnaire and the 
coefficient $\alpha$ is shown in Table 1 . In this paper, we use the items in the scale, which are quite mature options in the field of enterprise management. The questionnaire has stable and good validity.

Cronbach's alpha coefficient is the consistency between the scores of the various questions in the evaluation scale and belongs to the internal consistency coefficient. This method is suitable for the reliability analysis of attitude and opinion questionnaires. It is currently the most commonly used reliability coefficient. Its formula is

$$
\alpha=\frac{k \bar{\gamma}}{1+(k-1) \gamma} .
$$

Among them, $k$ is the total number of questionnaires, and $\bar{\gamma}$ is the mean value of the item correlation coefficient. This article uses $\alpha$ coefficient to analyze the reliability and validity of the questionnaire used in this article.

\section{Results and Discussion}

The overall scores of each dimension of shared leadership of the corporate management team are shown in Table 2. The sharing of power and responsibility is the most deficient. Among the four dimensions, the average score of power and responsibility sharing is the lowest, only 3.154, and the lowest evaluation given by the management team is 1.00 , and the highest evaluation is only 4.83 (not up to 5), which is significantly different from the highest evaluation obtained by the other three dimensions, which indicates that most of the management teams in enterprises have made a more negative evaluation on the team's practice in power and responsibility sharing. This reveals that the power and responsibility sharing degree of the enterprise management team is generally at a low level, and the mainstream management method in the team is still the centralization of one leader (absolute commander) and the obedience of other members. The decentralization of leadership, the equal relationship between members and leaders, and members' participation in team decision-making are not fully reflected, so it is difficult for team members to have more opportunities to participate in leadership and influence teamwork. In particular, for the original leaders in the team, it is contrary to their previous leadership style to transfer their leadership power and follow the leadership of other members, which is not well accepted by most enterprises [29].

Figure 1 shows the proportion of different coupling stages of leadership innovation. The proportion of the four scale enterprises in different coupling stages is different. Most of the large-scale enterprises are in the stage of high coupling (41.80\%) and moderate coupling (27.34\%). Most of the medium-sized enterprises are highly coupled (39.50\%) and moderately coupled (31.50\%). Most small enterprises are in the stage of moderate coupling $(40.72 \%)$, low coupling (33.20\%), and high coupling (25.9\%). Most of the microenterprises are in the stage of low coupling (43.70\%), moderate coupling $(36.41 \%)$, and high coupling $(30.51 \%)$. There are no fully coupled and uncoupled enterprises in the four types of scale enterprises. In contrast, the coupling degree of large enterprises is better than that of mediumsized enterprises, and the coupling degree of medium-sized enterprises is better than that of small enterprises, which is obviously better than that of microenterprises.

The descriptive statistics of financing risk indicators are shown in Figure 2. By analyzing the financing risk indicators in the data, it can be seen that the average quick ratio of the company is 0.0212 , the maximum value is 0.1149 , and the minimum value is 0.0046 . The company's short-term debt solvency is relatively average, and the overall situation is good; secondly, the standard deviation of the accounts receivable turnover rate is 0.0185 , the maximum value is 0.1016 , and the minimum value is 0.0014 . The period from acquisition to the final collection of corporate accounts receivable is short. Therefore, the industry's accounts receivable have strong liquidity, strong short-term debt solvency, and high-risk resistance. The average long-term debtto-asset ratio is 7.0684 , and the standard deviation is 45.5728. The long-term debt risk of enterprises varies greatly, and the long-term debt solvency is uneven.

The division interval of each category is shown in Table 3. When the target company's comprehensive negative entropy value is greater than 0.59 , it is classified as $A 1$, and the financial status of the company is very good, and its ability level in all aspects is high; when the target company's comprehensive negative entropy value is between 0.53 and 0.59 , it is $A 2$ Class, although its financial status is not as good as $A 1$, its overall capabilities are higher than most companies in the industry; when the comprehensive negative entropy value of the target company is between 0.46 and 0.53 , it is Class $B$, and the financial status of the company is at the industry average level, to avoid the deterioration of the financial situation and, at the same time, try to find ways to optimize the financial situation; when the comprehensive negative entropy value of the target company is between 0.40 and 0.46 , that is, $C 1$, it indicates that there are already some problems in the internal management of the company. The performance in all aspects is not satisfactory, and the company is in a relatively poor financial situation, and the company should take it seriously; when the comprehensive negative entropy of the target company is less than 0.40 , that is, category $C 2$, companies in the $C 2$ category should be vigilant, and the financial status of the company is already poor. Therefore, enterprises should actively take effective measures in response to their specific conditions.

The average value of financial indicators for each category is shown in Figure 3. It can be seen from the figure that the profitability indicators, solvency indicators, and cash flow levels of the $A 1$ category are significantly better than the other four categories while the growth ability indicators of the $A 1$ category are relatively weaker than the $A 2$ category, which is due to the $A 1$ category companies. Most of them are at the highest level in the industry and are large in scale, and their room for growth is relatively smaller than that of the $A 2$ category; and in the operating capacity indicators, the $A 1$ category's accounts receivable turnover rate is better than $A 2$, while the inventory turnover rate and current asset turnover rate are slightly weaker than category $A 2$. All indicators of category $B$ are at the average level of the industry, 
TABLE 1: Reliability and $\alpha$ coefficient comparison table.

\begin{tabular}{lr}
\hline Credibility & $\alpha$ coefficient \\
\hline Untrustworthy & $\alpha$ coefficient $<0.3$ \\
Barely believable & $0.3 \leq \alpha$ coefficient $<0.4$ \\
Credible & $0.4 \leq \alpha$ coefficient $<0.5$ \\
Very credible (most common) & $0.5 \leq \alpha$ coefficient $<0.7$ \\
Very credible (second common) & $0.7 \leq \alpha$ coefficient $<0.9$ \\
Very credible & $0.9 \leq \alpha$ coefficient \\
\hline
\end{tabular}

TABLe 2: The overall score of each dimension of shared leadership of the corporate management team.

\begin{tabular}{lcccc}
\hline & Power and responsibility sharing & Common expectation & Team learning & Team cooperation \\
\hline Minimum & 1.00 & 2.25 & 1.00 & 1.67 \\
Max & 4.83 & 5.00 & 5.00 & 5.00 \\
Average value & 3.154 & 3.852 & 3.760 & 3.652 \\
Standard deviation & 0.932 & 0.577 & 0.796 & 0.740 \\
\hline
\end{tabular}

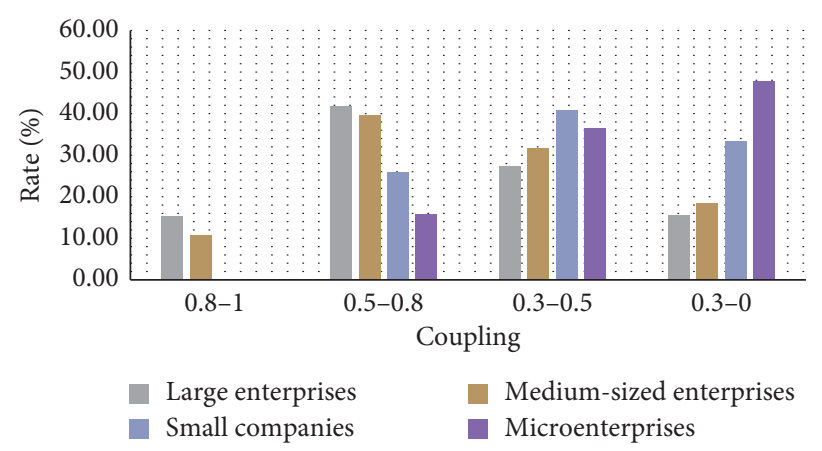

FIGURE 1: The proportion of different coupling stages of leadership innovation.

with poor performance in all aspects, while the financial indicators of category $C$ are obviously at the bottom of the industry, which is quite different from category $A$ companies, and has equal capabilities in all aspects. The performance is poor.

The model-fitting results of leadership development and corporate performance are shown in Table 4. The direct effect of leadership development on corporate performance is 0.074 , and it has not passed the significance test $(P$ value is 0.631). The direct impact of leadership development on corporate performance is not obvious. The positive impact of strategy formulation and execution on corporate performance is verified in this research (path coefficient is $0.394 ; P$ value is 0.002). The positive impact of transformational leadership on corporate performance is also verified in this article (path coefficient is $0.336 ; P$ value is 0.001 ). The positive impact of corporate culture adaptation and assimilation on corporate performance has also been verified again (path coefficient is $0.261 ; P$ value is 0.001 ). The path coefficient for leadership development to influence corporate performance through strategy formulation and execution is 0.323 , and the $P$ value is 0.003 , which passes the significance test at the $5 \%$ level.

The direct effect coefficient and $T$ value of the structural equation model are shown in Figure 4. The SEM path analysis results show that among the 19 hypothetical relationships in this study, the $T$ values (absolute value) of the direct effect coefficients of the hypotheses $\mathrm{H} 1 \mathrm{c}, \mathrm{H} 4 \mathrm{a}$, $\mathrm{H} 4 \mathrm{~b}$, and $\mathrm{H} 4 \mathrm{c}$ are all less than the minimum acceptable value of 1.96, so the null hypothesis is rejected. The absolute value of the direct effect coefficients of the remaining 15 hypothetical relationships is between 0.10 and 0.96 , and the $T$ value (absolute value) is between 2.11 and 16.98, which are all greater than 1.96, so the null hypothesis is accepted. Small and medium-sized enterprises are smaller than large enterprises in terms of scale, personnel, asset ownership, and influence. They have weak capital power and a shortage of talent development funds, so they cannot provide competitive remuneration packages. In addition, small and medium-sized enterprises have weaknesses in management systems, technological innovation, industrial structure, and antirisk capabilities, which restrict the development of small and medium-sized enterprises, and the development prospects of enterprises are very uncertain, which eventually leads to some technical and management backbones that are easy to be dug by means such as high salaries. If you leave, some employees with technical or marketing advantages will leave the company to enter the world. The loss and lack of talents directly affect the development of SME leadership.

The results of the employee satisfaction survey are shown in Figure 5. The democratic style has higher employee satisfaction and the authoritarian style is lower. The 


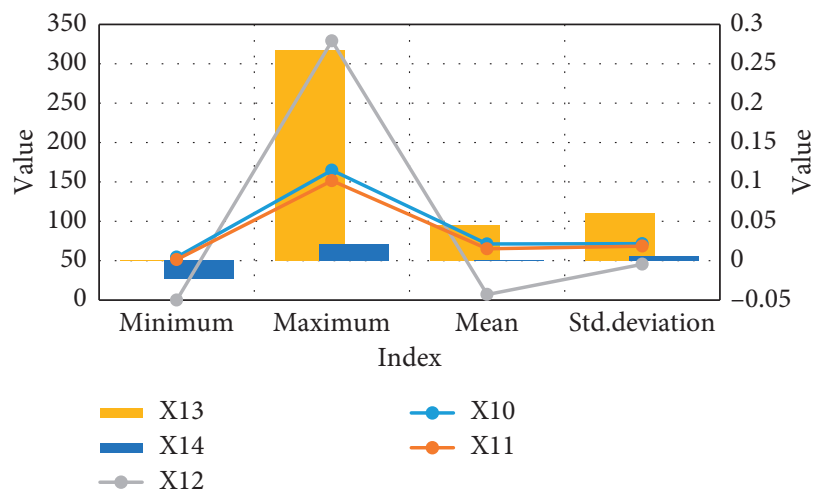

Figure 2: Descriptive statistics of financing risk indicators.

TABLE 3: Division of each category.

\begin{tabular}{lccccc}
\hline Category & $A 1$ & $A 2$ & $B$ & $C 1$ & $C 2$ \\
\hline Interval & $x>0.59$ & $0.53<x<0.59$ & $0.46<x<0.53$ & $0.40<x<0.46$ & $x<0.40$ \\
\hline
\end{tabular}

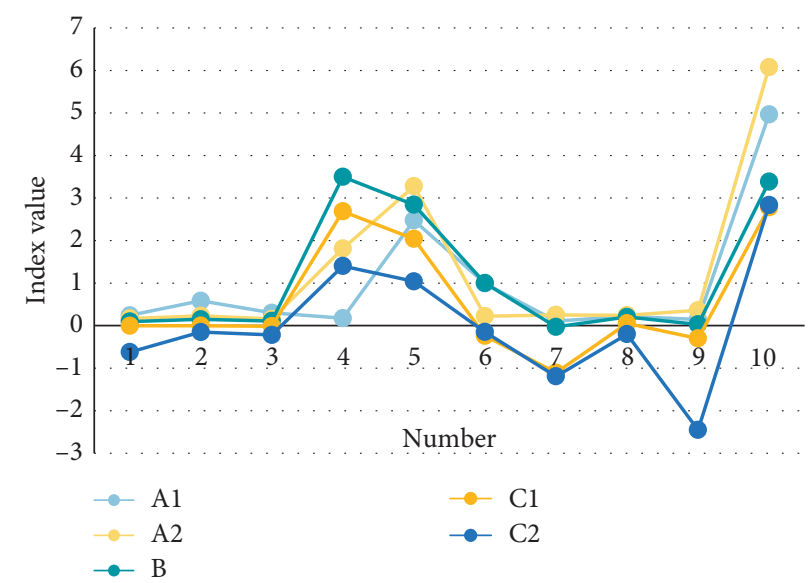

Figure 3: Means of financial indicators for each category.

TABLE 4: Model-fitting results of leadership development and corporate performance.

\begin{tabular}{|c|c|c|}
\hline Path & $\begin{array}{l}\text { Estimated } \\
\text { value }\end{array}$ & $\begin{array}{c}P \\
\text { value }\end{array}$ \\
\hline Corporate performance $(\mathrm{F}) \leftarrow$ leadership development $(\mathrm{A})$ & 0.074 & 0.613 \\
\hline Corporate performance $(\mathrm{F}) \leftarrow$ strategy formulation and execution $(\mathrm{C})$ & 0.394 & 0.002 \\
\hline Corporate performance $(\mathrm{F}) \leftarrow$ transformational leadership behavior (D) & 0.336 & 0.001 \\
\hline Corporate performance $(\mathrm{F}) \leftarrow$ corporate culture adaptation and assimilation (E) & 0.261 & 0.001 \\
\hline $\begin{array}{l}\text { Corporate performance }(\mathrm{F}) \leftarrow \text { transformational leadership behavior }(\mathrm{D}) \leftarrow \text { organizational leadership }(\mathrm{B}) \leftarrow \\
\text { leadership development }(\mathrm{A})\end{array}$ & 0.195 & 0.001 \\
\hline Corporate performance $(\mathrm{F}) \leftarrow$ strategy formulation and execution $(\mathrm{C}) \leftarrow$ leadership development $(\mathrm{A})$ & 0.323 & 0.003 \\
\hline Corporate performance $(\mathrm{F}) \leftarrow$ corporate culture adaptation and assimilation $(\mathrm{E}) \leftarrow$ leadership development $(\mathrm{A})$ & 0.169 & 0.002 \\
\hline
\end{tabular}

democratic employee satisfaction rate is $74.8 \%$, the laissezfaire employee satisfaction rate is $61.7 \%$, and the authoritarian employee satisfaction rate is $48.6 \%$. High employee satisfaction means high leadership effectiveness; low employee satisfaction means low leadership effectiveness. This reflects from the side that the more similar the leadership style to strategic leadership, the higher the employee satisfaction, and the employee satisfaction is regarded as the strategic leadership effectiveness. A detection index is feasible, which is to decompose the strategic leadership effectiveness index from the individual level.

The survey results of employee innovation ability and organizational performance are shown in Figure 6. There is a positive correlation between employee innovation ability and organizational performance and satisfaction. The democratic employee innovation ability and organizational 


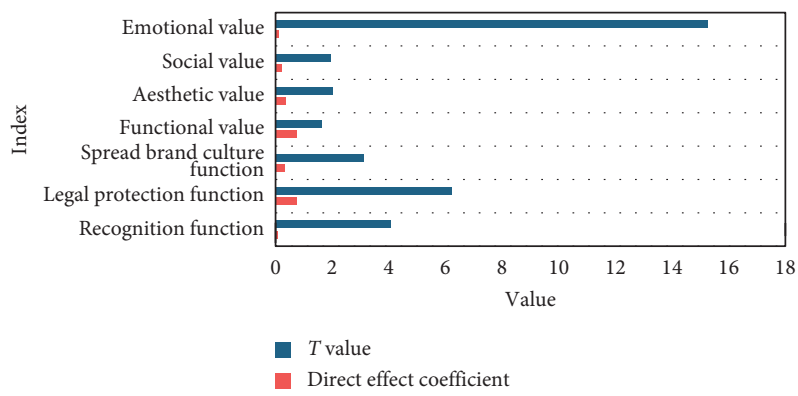

Figure 4: The direct effect coefficient and $T$ value of the structural equation model.

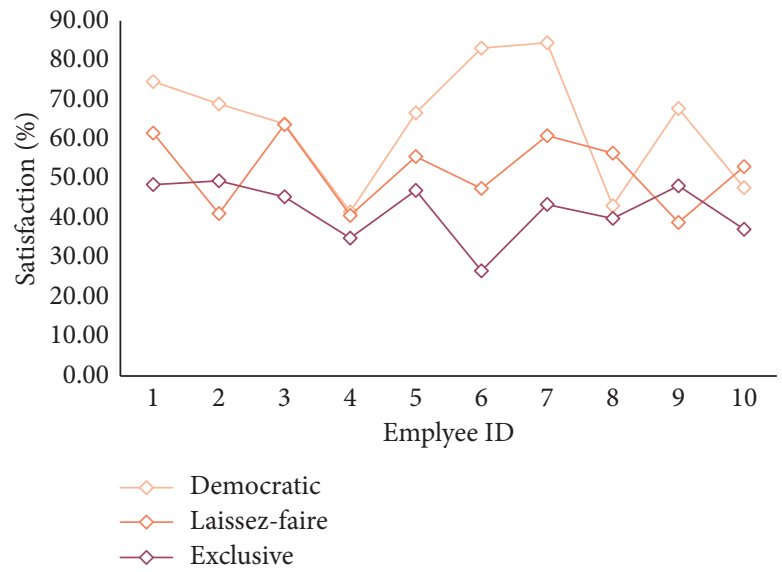

FiguRE 5: Employee satisfaction survey results.

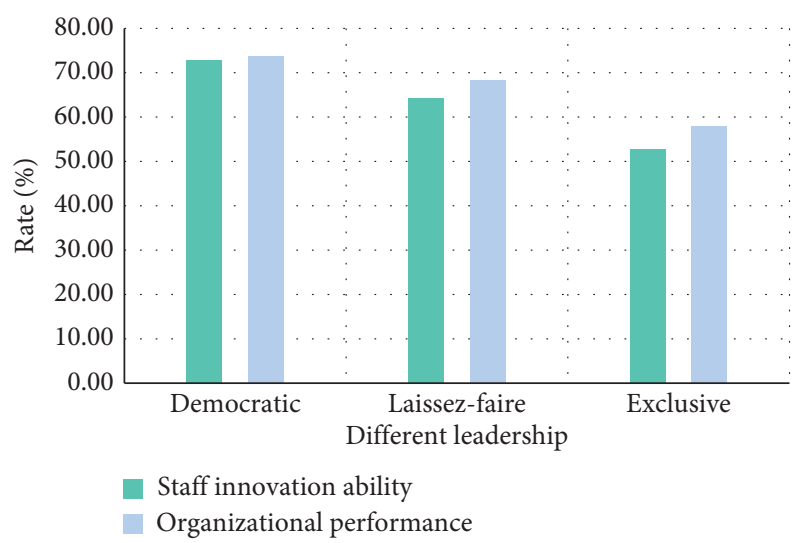

FIGURE 6: Survey results of employee innovation ability and organizational performance.

performances are $72.8 \%$ and $73.7 \%$, respectively, the laissezfaire type is $64.3 \%$ and $68.4 \%$, and the exclusive type is $52.7 \%$ and $57.9 \%$, respectively. Organizational performance and leadership effectiveness are closely linked, and the level of organizational performance reflects the size of leadership effectiveness. From the survey results, it is found that the innovation ability of employees is positively correlated with organizational performance. The higher the innovation ability, the better the organizational performance, and the innovation ability is related to the path leadership of strategic leadership and continuous leadership, so strategic leadership can promote the improvement of corporate organizational performance. Effective use of strategic leadership can not only lead the corporate organization through difficulties but also promote the sustainable development of the corporate organization. 


\section{Conclusion}

This paper discusses the performance-oriented leadership improvement program for middle managers. The design idea of the scheme is divided into two lines. Through the company's common training plan and self-driven personal development plan, and the guidance of department managers, coaches, and referees, the performance goal and development plan are implemented, and the ability is improved through the goal. The overall plan is based on the establishment of the company's strategy and business objectives as the starting point, target management throughout, so that the enterprise is consistent, horizontal integration, to build a corporate governance model based on the company's strategy, through the operation, performance, personnel training, internal cooperation, and other systems. The leadership promotion program is divided into "internal promotion" and "external promotion". On the one hand, it guides the middle-level managers to improve themselves; on the other hand, from the perspective of enterprises, it formulates promotion countermeasures and safeguards from four aspects of talent selection, employment, training, and assessment. The leadership development program with multilevel countermeasures and safeguard measures will play a positive role in promoting the leadership of middlelevel managers. All departments will fully cooperate, grasp all kinds of opportunities, deeply refine the program, and make a thorough understanding of it, which will surely cultivate an excellent middle-level management team for the enterprise and bring development advantages for the enterprise.

\section{Data Availability}

No data were used to support this study.

\section{Conflicts of Interest}

The authors declare that they have no conflicts of interest.

\section{Acknowledgments}

This work was supported by the fund of "Demonstration Course of Ideological and Political in Microeconomics "(no. qhnukcszk016) and the fund of "Research on the Development of Wellness Tourism in Qinghai in the New Era" (no. 18029).

\section{References}

[1] K. Kasztelnik and D. Brown, "Perceived effective business ethics through leadership and cultural competence in the United States," Business Ethics and Leadership, vol. 3, no. 4, pp. 15-27, 2019.

[2] E. D. Putra and S. Cho, "Characteristics of small business leadership from employees' perspective: a qualitative study," International Journal of Hospitality Management, vol. 78, no. 4, pp. 36-46, 2019.

[3] D. Hdrolu, "Strategic leadership: best practical leadership style to business strategies in the Period of covid-19 epidemic,"
Turkish Studies - Social Sciences, vol. 15, no. 4, pp. 1945-1955, 2020.

[4] A. Tharwat, A. Osama, Munim et al., "The impact of artificial intelligence techniques on the entrepreneurship of the leadership of international business organizations - a suggested model -an analytical study," International Journal of Innovative Research in Science Engineering and Technology, vol. 5, no. 8, pp. 739-747, 2020.

[5] K. Starr, "What future for school business leadership? Recent change and looming possibilities," Management in Education, vol. 35, no. 3, pp. 1-9, 2020.

[6] T. Goncharenko, "From business modelling to the leadership and innovation in business: bibliometric analysis (banking as a case)," Business Ethics and Leadership, vol. 4, no. 1, pp. 113-125, 2020.

[7] C. J. Hahn and J. E. Gangeness, "Business, leadership and education: a case for more business engagement in higher education," American Journal of Business Education (AJBE), vol. 12, no. 1, pp. 19-32, 2019.

[8] J. Stoner, "Business school leadership for a sustainable, flourishing, and regenerating world," Journal of Management for Global Sustainability, vol. 7, no. 2, pp. 1-10, 2019.

[9] F. Y. Fok-Yew Oon, A. Abdul Hamid Nor Aziati, and A. Abu Seman Esmadi Abu, "Business excellence, leadership and lean: a systematic literature review," International Journal of Business and Society, vol. 22, no. 1, pp. 332-345, 2021.

[10] G. R. Jackson, "Overcoming small to medium business failure through leadership strategies," Open Journal of Business and Management, vol. 9, no. 1, pp. 353-384, 2021.

[11] K. Mitsuru, "Business innovation through holistic leadershipdeveloping organizational adaptability," Systems Research and Behavioral Science, vol. 36, no. 4, pp. 365-394, 2019.

[12] B. Unhelkar and T. Gonsalves, "Enhancing artificial intelligence decision making frameworks to support leadership during business disruptions," IT Professional, vol. 22, no. 6, pp. 59-66, 2020.

[13] C. Akhras, "A hope impact in MENA: business leadership and job performance," International Journal of Psychosocial Rehabilitation, vol. 24, no. 1, pp. 898-906, 2020.

[14] C. E. Nwachukwu and V. M. Hieu, "Strategic flexibility, strategic leadership and business sustainability nexus," International Journal of Business Environment, vol. 11, no. 1, pp. 125-143, 2020.

[15] W. Wu, Y. Liu, C. H. Wu, and S. B. Tsai, "An empirical study on government direct environmental regulation and heterogeneous innovation investment," Journal of Cleaner Production, vol. 254, Article ID 120079, 2020.

[16] M. Lusiani, Z. Abidin, D. Fitrianingsih et al., "Effect of servant, digital and green leadership toward business performance: evidence from Indonesian manufacturing," Systematic Reviews in Pharmacy, vol. 11, no. 11, pp. 1351-1361, 2020.

[17] C. B. Scheepers and J. Bogie, "Uber Sub-Saharan Africa: contextual leadership for sustainable business model innovation during COVID-19," Emerald Emerging Markets Case Studies, vol. 10, no. 3, pp. 1-18, 2020.

[18] A. A. M. Saiyed, "The role of leadership in business model innovation: a case of an entrepreneurial firm from India," New England Journal of Entrepreneurship, vol. 22, no. 2, pp. 70-88, 2019.

[19] S.-B. Tsai, C.-Y. Huang, C.-K. Wang et al., "Using a mixed model to evaluate job satisfaction in high-tech industries," PLoS One, vol. 11, no. 5, Article ID e0154071, 2016.

[20] M. Alharthi, G. Khalifa, A. Abuelhassan, M. Nusari, and O. Isaac, "Investigating the impact of leadership and business 
continuity management on organizational crisis performance," International Business Management, vol. 13, no. 7, pp. 266-278, 2019.

[21] B. Ida and I. G. Riana, "Predicting business performance through leadership style and job motivation," International Research Journal of Management IT and Social Sciences, vol. 6, no. 5, pp. 184-192, 2019.

[22] A. Qasim and J. Suhair Adel, "The relationship between strategic improvisation and entrepreneurial performance: analytical research in the ministry of agriculture," Journal of Contemporary Issues in Business and Government, vol. 27, no. 3, pp. 1030-1039, 2021.

[23] B. G. Mujtaba, "Leadership and management philosophy of "guzaara" or cooperating to "get along" in South Asia's Afghanistan," Business Ethics and Leadership, vol. 3, no. 1, pp. 44-57, 2019.

[24] S. N. Singh, "Private investment and business opportunities in Ethiopia: a case study of Mettu Town in Ethiopia," Business Ethics and Leadership, vol. 3, no. 4, pp. 91-104, 2019.

[25] A. Bonamigo and D. Mendes, "Value co-creation and leadership: an analysis based on the business ecosystem concept," Business Ethics and Leadership, vol. 3, no. 4, pp. 66-73, 2019.

[26] A. Malik, N. Khan, S. Faisal et al., "An investigation on leadership styles for the business productivity and sustainability OF small medium enterprises (SME'S)," International Journal of Entrepreneurship, vol. 25, no. 5, pp. 1-10, 2021.

[27] J. Clifton, "Investigating the dark side of stories of "good" leadership: a discursive approach to leadership gurus' storytelling," International Journal of Business Communication, vol. 56, no. 1, pp. 82-99, 2019.

[28] N. Eva, S. Sendjaya, D. Prajogo, and K. Madison, "Does organizational structure render leadership unnecessary? Configurations of formalization and centralization as a substitute and neutralizer of servant leadership," Journal of Business Research, vol. 129, no. 5, pp. 43-56, 2021.

[29] S.-B. Tsai, "Using the DEMATEL model to explore the job satisfaction of research and development professionals in China's photovoltaic cell industry," Renewable and Sustainable Energy Reviews, vol. 81, pp. 62-68, 2018. 